九州大学学術情報リポジトリ

Kyushu University Institutional Repository

\title{
A COMPARATIVE MORPHOLOGY OF THE ALIMENTARY CANAL IN THE ADULTS OF GROUND-BEETLES (COLEOPTERA) I. CLASSIFICATION INTO THE TYPES
}

Yahiro, Katsuro

https://doi.org/10.5109/2524

出版情報 : ESAKIA. Special Issue 1, pp.35-44, 1990-04-20. Entomological Laboratory, Faculty of Agriculture, Kyushu University

バージョン：

権利関係 : 


\title{
A COMPARATIVE MORPHOLOGY OF THE ALIMENTARY CANAL IN THE ADULTS OF GROUND-BEETLES (COLEOPTERA) I. CLASSIFICATION INTO THE TYPES
}

\author{
KATSURO YAHIRO \\ Entomological Laboratory, Faculty of Agriculture, \\ Kyushu University, Fukuoka, 812 Japan
}

\begin{abstract}
The alimentary canal in the adult of ground-beetles has been investigated for 43 species belonging to 26 genera, 16 subfamilies in 2 families on such important characters as crypts, proventriculus and meandering of the guts. Their alimentary canal can be classified into 7 types by their structures as follows: I, Carabinae-type ; II, Nebriinaetype ; III, Elaphrinae-type ; IV, Scaritinae- type ; V, Bembidiinae- type ; VI, Pterostichinae-type ; and VII, Callistinae-type.
\end{abstract}

\section{Introduction}

The ground-beetles constitute one of the largest groups in the Coleoptera, and are represented by more than 1000 species in Japan. Many attempts had been made to establish the higher classification system of this group, but no satisfactory system has been presented from the view point of the phylogenetic systematics.

This is my first paper on the comparative morphology of the alimentary canal in the groundbeetles in order to provide some basic data for a study of the higher classification. Studies of the alimentary canal have been made on various groups of the Coleoptera (Umeya 1960 ; Ekis and Gupta 1971; Kasap 1879 ; Youping 1987 ; etc.). The morphology and histology of the alimentary canal had been examined for the following ground-beetles, Sphaeroderus nitidicollis Chev. var. schaumi Chaudoir by Schaefer (1931), Calosoma sycophanta Linnaeus by Bess (1935), Harpalus sylvanicus Dejean by Whittington (1935), and Nebria brebicollis Linnaeus by Carleton (1936). Poll (1932) had been examined the malpighian tubules of Carabidae. Balfour-Browne (1944) compared the proventriculus of the ground-beetles. Judd (1947, 1948) studied on Chlaenius sp. Reichenbach-Klinke (1953) made a study on the proventriculus of the Carabidae. Ali (1967) studied on the internal anatomy of the Carabidae. Smri (1982) made some phylogenetic notes on the Adephaga based on the comparative anatomy of the proventriculus. Elliott \& King (1985) studied on the rectal pad structure in some terrestrial and intertidal ground-beetles. In this paper, 43 species belonging to 26 genera, 16 subfamilies in 2 families, and their phylogenetic significances are discussed on the structures of the crypts

* Contribution from the Entomological Laboratory, Faculty of Agriculture, Kyushu University, Fukuoka (Ser. 4, No. 4). 
and proventriculus, and on the meandering pattern of the guts.

\section{Materials and Methods}

In the present investigation, living or preserved specimens in $70 \%$ alcohol were used. After measuring the body length, the elytra are removed, and dissected in about $80 \%$ alcohol by the aid of two forceps with sharpened apices under a binocular stereoscope. The thoracic nota and the abdominal terga were removed, then the alimentary canals were taken out from the bodies and examined in detail. They were drawn by myself and were finally measured for comparison.

The species examined are listed in Table 1, all of which were identified by myself.

Table 1. List of the species examined.

\begin{tabular}{|c|c|}
\hline Family, Subfamily & Species [Locality* (No. of examined specimens)] \\
\hline \multicolumn{2}{|l|}{ Carabidae } \\
\hline Carabinae & $\begin{array}{l}\text { Carabus japonicus japonicus Motschulsky [KO (6)]; C. dehaanii dehaanii Chaudoir [TF } \\
\text { (4), HF (6)]; Leptocarabus opaculus opaculus (Putzeys) [TH (4)]; Damaster blaptoides } \\
\text { blaptoides Kollar [AF (3), SF (2)];D. b. rugipennis (Motschulsky) [TH (3)]; D. fruh- } \\
\text { storferi (Roeschke) [ON (1)] }\end{array}$ \\
\hline Nebriinae & Nebria chinensis Bates $[\mathrm{AF}(4)] ;$ N.macrogona Bates $[\mathrm{KO}(5)]$ \\
\hline Elaphrinae & Elaphrus comatus Goulet [NH (3)] \\
\hline Scaritinae & Scarites acutidens Chaudoir $[\mathrm{KF}(2)]$ \\
\hline Broscinae & Broscoma doenitzi (Harold) [TS (2)] \\
\hline Trechinae & Trechus ephippiatus Bates [CY (2)] \\
\hline \multirow[t]{3}{*}{ Bembidiinae } & Bembidion morawitzi Csiki $[\mathrm{KO}(5)]$ \\
\hline & B. semiluitum Bates $[\mathrm{KO}(2)]$ \\
\hline & Asaphidion semilucidum (Motschulsky) [MO (1)] \\
\hline Patrobinae & Apatrobus hikosanus (Habu) [TS (2)]; Diplous caligatus Bates [KO (3)] \\
\hline Pterostichinae & $\begin{array}{l}\text { Pterostichus planicollis (Motschulsky) }[\mathrm{KO}(3)] ; P \text {. sp. [TH (2)]; Platynus magnus } \\
\text { (Bates) [GH (3)]; Agonum ogurae (Bates) [SS (2)]; Colpodes aequatus Jedrička [SS } \\
(4)] ; \text { Dolichus halensis (Schaller) }[\mathrm{HF}(4)]\end{array}$ \\
\hline Zabrinae & Amara congrua Morawitz $[\mathrm{HF}(2)]$ \\
\hline Harpalinae & $\begin{array}{l}\text { Harpalus jureceki (Jedrička) }[\mathrm{HF}(4)] \text {; H. tridens Morawitz }[\mathrm{HF}(4)] \text {; H. sinicus Hope } \\
{[\mathrm{HF}(3)] ; \text { H. capito Morawitz }[\mathrm{HF}(1)] \text {; H. chalcentus Bates }[\mathrm{HF}(1)]}\end{array}$ \\
\hline Panagaeinae & Dischissus japonicus Andrewes [TN (5)] \\
\hline Callistinae & $\begin{array}{l}\text { Haplochlaenius costiger (Chaudoir) [AF (2)];Chlaenius circumductus Morawitz [NH } \\
\text { (2)]; C. micans (Fabricius) [KO (2)] ; C. naeviger Morawitz }[\mathrm{HS}(3)]\end{array}$ \\
\hline Odacanthinae & Archicolliurisbimaculatanipponica Habu [HO (1)] \\
\hline Libiinae & Lebidia octoguttata Morawitz [KO (2)]; Lebia hikosana Habu [HF (2)] \\
\hline Zuphiinae & Galerita orientalis Schmidt-Göbel [MF (2), SF (1)] \\
\hline Brachinidae & $\begin{array}{l}\text { Pheropsophus jessoensis Morawitz [YY (3)]; P.javanus (Dejean) [AK (2)]; Brachinus } \\
\text { stenoderus Bates [KO (2)] }\end{array}$ \\
\hline
\end{tabular}

*KO=Kuju, Oita Pref. ; TF=Mt. Tachibana, Fukuoka Pref. ; HF=Mt. Hikosan, Fukuoka Pref. ; TH= Tokachi-mitsumata, Hokkaido ; AF=Amagi, Fukuoka Pref. ; SF= Sawara-ku, Fukuoka Pref. ; ON = Ofunato, Nagasaki Pref. ; NH=Nukabira, Hokkaido ; KF=Kuroki-cho, Fukuoka Pref. ; TS= Mt. Taradake, Saga Pref. ; CY =Chomon-kyo, Yamaguchi Pref. ; MO=Makinoto Pass, Oita Pref. ; GH =Geihoku-cho, Hiroshima Pref. ; SS = Mt. Sefuri, Saga Pref. ; TN = Mt. Tatera, Nagasaki Pref. ; HS = Hikimi-kyo, Shimane Pref. ; HO= Handa, Oita Pref. ; MF=Mt. Mikazuki, Fukuoka Pref. ; SF=Soeda-cho, Fukuoka Pref. ; YY = Yoshida, Yamaguchi Pref. ; AK=Amami-Oshima Is., Kagoshima Pref. 


\section{Results}

\section{General structure of the alimentary canal (Fig.1).}

General structure of the alimentary canal is outlined as follows:

The alimentary canal is divided into three parts, namely the fore, mid and hind guts.

The fore gut. The fore gut is a tube from opening of the mouth to the oesophageal valve, and consists of the oesophagus, crop and proventriculus. In the ground-beetles, the fore gut is mainly occupied by the oesophagus and crop, and the proventriculus is short. The fore gut is situated in the center of body and does not curve nor meander in general. Its surface is almost smooth. The oesophagus is straight and thin in general. The crop is a sac with thin wall and situated in the mesoand metathoraxes. The fore gut has functions as storaging and crushing foods, and mixing saliva with foods, etc.

The mid gut. The mid gut is a tube from the oesophageal valve to the pyloric valve. The mid gut has function of digesting and absorbing foods. It is almost straight in general but curves or meanders in several species. There are small diverticulum projections (crypts) on the surface of the mid gut.

The hind gut. This is the last part of the alimentary canal posterior to the pyloric valve of the mid gut. It consists of the ileum, colon and rectum. The malpighian tubules originate from the base

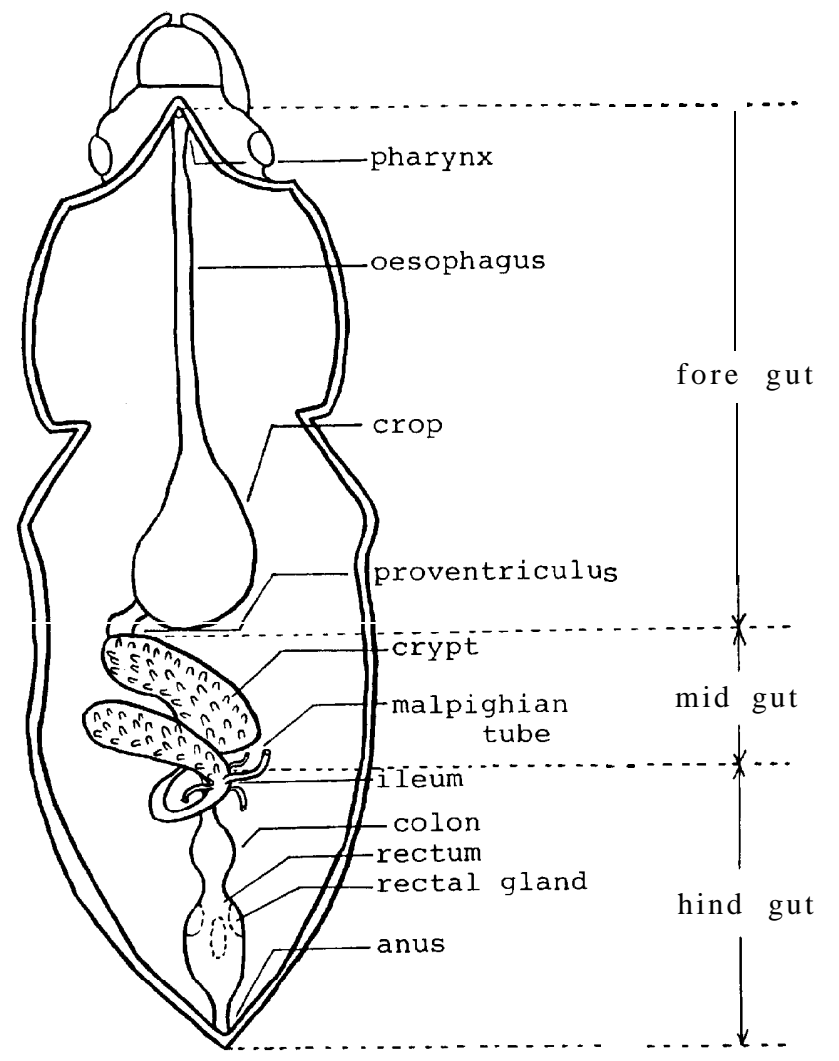

Fig. 1. General structure of the alimentary canal of the ground-beetles. 
of the ileum, and are composed of two pairs of the tubules. The ileum has function as absorption of water from digested foods. The colon is indistinct and the rectum is generally straight.

\section{Comparative morphology}

Carabidae

Carabinae (Figs. Z-5). Fore gut with oesophagus straight and thin ; crop large, bulbous ; proventriculus broadest at anterior part, then gradually narrowed posteriorly. Mid gut straight and then meander at posterior part ; crypts larger and different on anterior part from those on posterior part. Hind gut with ileum meandering ; rectum thin, not distinctly demarcated from ileum ; rectal gland elliptical in shape, lying in a ring around anterior part of rectum. Ratio in length of the mid gut to that of whole length is high except for Damaster fruhstorferi (Roeschke).

Nebriinae (Figs. 6, 7). Fore gut with oesophagus straight and medium in thickness ; crop large, bulbous; proventriculus barrel-shaped with clear eight rows of spines. Mid gut crescent, then gradually narrowing posteriorly, anterior part about 5 times as broad as posterior part. Hind gut with ileum curved upward to right side, then meandering to the right S-shapedly ; rectum medium in size ; rectal glands elliptical in shape, lying in two close rings around the anterior part of rectum.

Elaphrinae (Fig. 8). Fore gut with oesophagus straight and medium in thickness, crop bulbous, posterior part twisted ; proventriculus about 2 times as long as broad. Mid gut straight and thick at anterior part, then curved to the right and forms one and half dextral coil before joining hind gut. Hind gut with ileum short, curved downward to the right side, then meandering to the right $\mathrm{S}$ shapedly ; rectum medium in size, rectal glands elliptical in shape, lying in a ring around anterior part of rectum.

Scaritinae (Fig. 9). Fore gut with oesophagus straight and medium in thickness ; crop very large, bulbous; proventriculus distinctly demarcated from crop by its posterior constriction, broadest at anterior part, then gradually narrowed posteriorly. Mid gut with anterior part thin, broadest at $1 / 5$, then gradually narrowing posteriorly and curved to the left to form one dextral coil, joining hind gut at the right side. Hind gut with ileum curved upward to right side, then meandering to the left Ushapedly, joining rectum at right angle; rectum medium in size.

Broscinae (Fig. 10). Fore gut with oesophagus straight and thin ; crop small ; proventriculus about 2 times as long as broad, lying obliquely in first abdominal segment. Mid gut with anterior part about 2 times as broad as posterior part, curved to the right to form one dextral coil, joining hind gut at the left side. Hind gut with ileum meandering S-shapedly ; rectum medium in size ; rectal glands elliptical in shape, lying in a ring around anterior part of rectum.

Trechinae (Fig. 11). Fore gut with oesophagus straight and thin ; crop small ; proventriculus about 3 times as long as broad. Mid gut straight. Hind gut with ileum straight, then curved to right side; rectum medium-sized ; rectal glands elliptical in shape, lying in a ring around anterior part of rectum.

Bembidiinae (Figs. 12-14). Fore gut with oesophagus straight and thin; crop small ; proventriculus not distinctly demarcated from crop, 2 times as long as broad. Mid gut straight. Hind gut with ileum curved to the right and forms one dextral coil from dorsal view ; rectum medium in size ; rectal glands globular in shape, lying in a ring around anterior part of rectum.

Figs. 2-16. Alimentary canal of the ground-beetles. 2, Leptocarabusopaculus opaculus (Putzeys) ; 3 , Damaster blaptoides blaptoides Kollar ; 4, D. b. rugipennis (Motschulsky) ; 5, D. fruhstorferi (Roeschke) ; 6, Nebria chinensis Bates ; 7, N. macrogona Bates ; 8, Elaphrus comatus Goulet ; 9, Scarites acutidens Chaudoir ; 10, Broscoma doenitzi (Harold) ; 11, Trechus ephippiatus Bates ; 12, Bembidion morawitzi Csiki ; 13, B. semiluitum Bates ; 14, Asaphidion semilucidum (Motschulsky) ; 15, Diplous caligatusBates; 16, Pterostichus planicollis (Motschulsky). Scales : $2.5 \mathrm{~mm}$. 


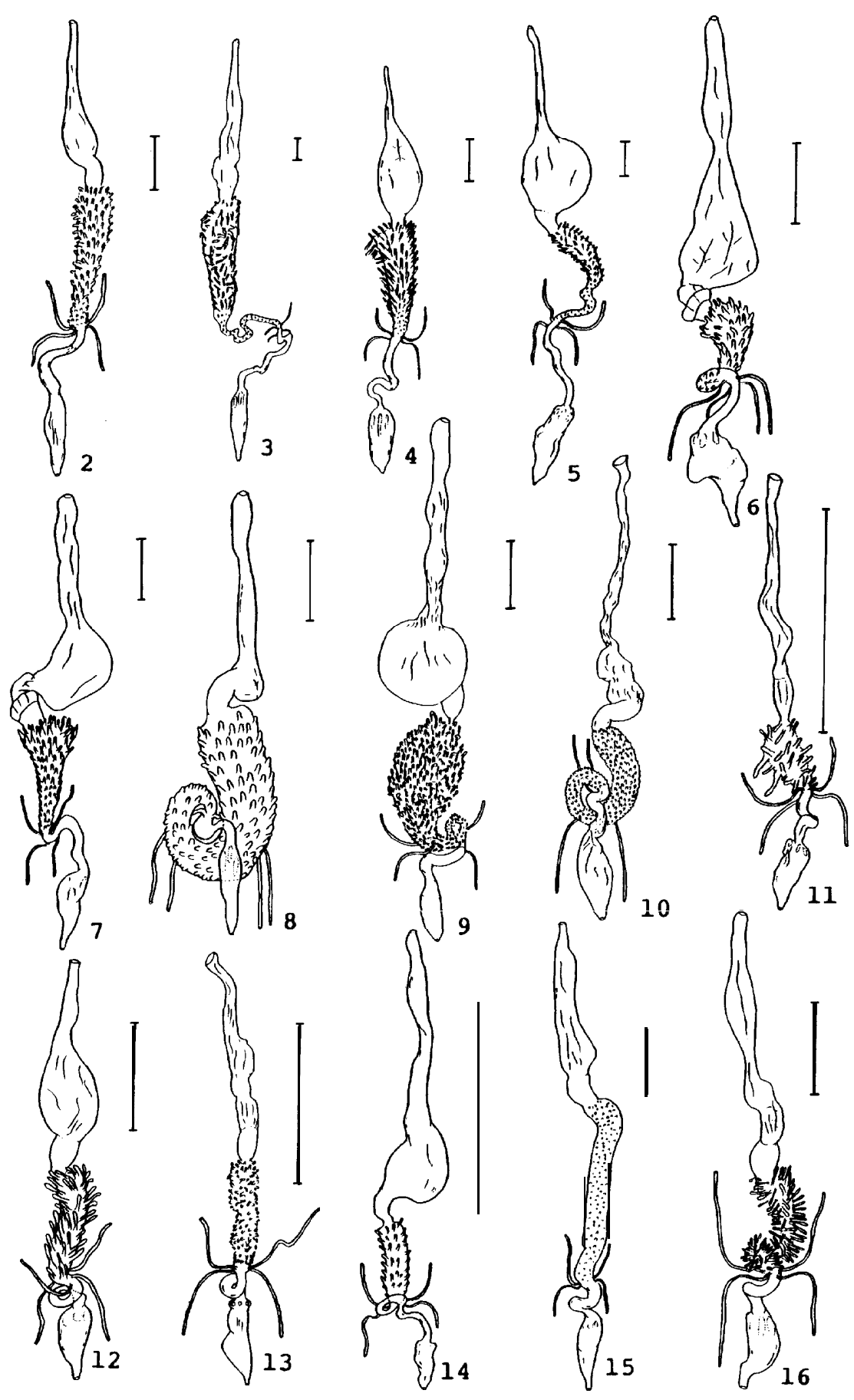


Patrobinae (Fig. 15). Fore gut with oesophagus straight and medium in thickness; crop small, proventriculus about 1.5 times as long as broad. Mid gut straight. Hind gut with ileum meandering to the right inverted S-shapedly ; rectum medium-sized ; rectal glands elliptical in shape, lying in a ring around anterior part of rectum.

Pterostichinae (Figs. 16-20). Fore gut with oesophagus straight and medium in thickness ; crop small, stick-shaped ; proventriculus about 1.5 times as long as broad. Mid gut straight at anterior part, then curved to right and forms one dextral coil at posterior part. Hind gut curved to right and forms one dextral coil ; rectum medium in size.

Zabrinae (Fig. 21). Fore gut with oesophagus straight and medium in thickness ; crop small ; proventriculus about 2 times as long as broad. Mid gut meandering to the right side. Hind gut with ileum meandering to the right S-shapedly ; rectum medium in size ; rectal glands elliptical in shape, lying in a ring around anterior part of rectum.

Harpalinae (Figs. 22, 23). Fore gut with oesophagus straight and thin ; crop small ; proventriculus about 3 times as long as broad. Mid gut curved to the left. Hind gut with ileum curved to the right and forms one dextral coil ; rectum medium in size ; rectal glands elliptical in shape, lying in a ring around anterior part of rectum.

Panagaeinae (Fig. 24). Fore gut with oesophagus straight and thin ; crop small ; proventriculus elliptical in shape, and thin ; crop small ; proventriculus elliptical in shape, about 2.5 times as long as broad. Mid gut with anterior with part about 2.8 times as broad as posterior part, curved to the right and form one dextral coil. Hind gut with ileum curved to the right and forms one dextral coil ; rectum thick ; rectal glands elliptical in shape, lying in a ring around anterior part of rectum.

Callistinae (Figs. 25, 26). Fore gut with oesophagus straight and medium in thickness ; crop small, proventriculus about 2.1 times as long as broad. Mid gut straight and posterior part meandering gently, thin. Hind gut with ileum meandering to the left, then to the right ; rectum thin.

Odacanthinae (Fig. 27). Fore gut with oesophagus straight and thin ; crop bulbous ; proventriculus elliptical in shape, about 2 times as long as broad. Mid gut short and straight. Hind gut with ileum meandering S-shapedly ; rectum medium in size ; rectal glands globular in shape, lying in a ring around anterior part of rectum.

Lebiinae (Figs. 28. 29). Fore gut with oesophagus straight and medium in thickness ; crop very large, bulbous ; proventriculus distinctly demarcated from crop by its posterior constriction, broadest at anterior part, then gradually narrowing posteriorly. Mid gut curved to the left, gradually narrowing posteriorly. Hind gut with ileum S-shaped ; rectum medium in size ; rectal glands elliptical in shape, lying in a ring around anterior part of rectum.

Zuphinae (Fig. 30). Fore gut with oesophagus straight and medium in thickness ; crop large, bulbous ; proventriculus about 2.8 times as long as broad. Mid gut straight, then posterior part curved to the right and forms one dextral coil ; rectum medium in size ; rectal glands elliptical in shape, lying in a ring around anterior part of rectum.

Brachinidae (Figs. 31, 32). Fore gut with oesophagus straight and medium in thickness ; crop large, bulbous ; proventriculus broadest at anterior part, then gradually narrowing posteriorly. Mid

Figs. 17-33. Alimentary canal of the ground-beetles. 17, P. sp. ; 18, Platynus magnus (Bates) ; 19, Agonum ogurae (Bates) ; 20, Dolichus halensis (Schaller) ; 21, Amara congrua Morawitz ; 22, Harpalus capito Morawitz ; 23, H. chalcentus Bates ; 24, Dischissus japonicus Andrewes; 25, Haplochlaenius costiger (Chaudoir) ;26, Chlaenius micans (Fabricius); 27, Archicolliuris bimaculata nipponica Habu ; 28, Lebidia octoguttata Morawitz ; 29, Lebia hikosana Habu ; 30, Galerita orientalis SchmidtGöbel ; 31, Pheropsophus jessoensis Morawitz ; 32, P. javanus (Dejean) ; 33, Brachinus stenoderus Bates. Scales : $2.5 \mathrm{~mm}$. 


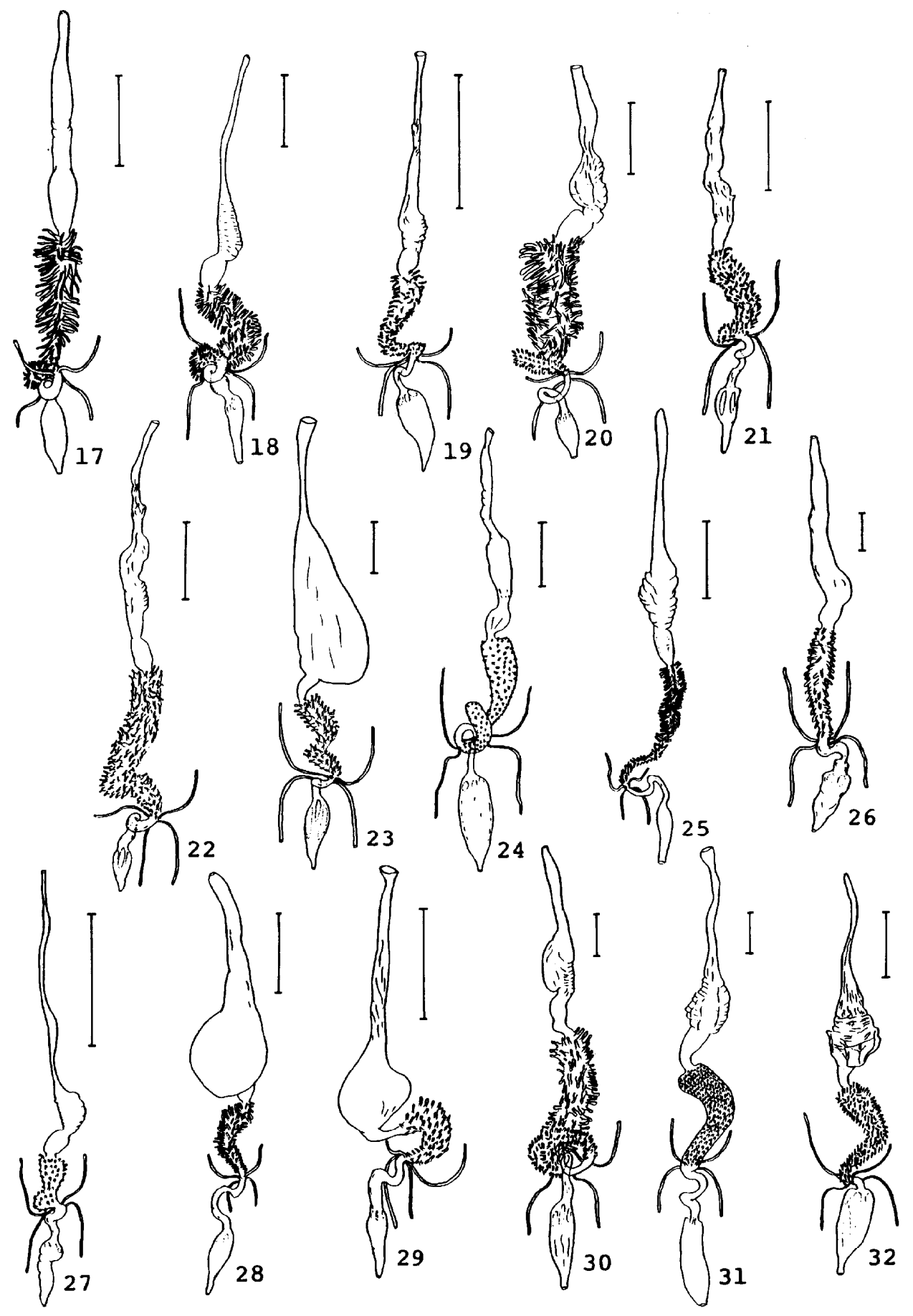


gut meandering to the right. Hind gut with ileum meandering to right and then meandering to left S-shapedly ; rectum medium in size.

\section{Discussion}

The alimentary canal of the ground-beetles can be divided into 7 types by the characters of the crypts and proventriculus, and by the meandering patterns of the mid and hind guts as follows :

1) Carabinae-type : Carabinae. The crypts on the anterior part of the mid gut is different in shape from those on the posterior part.

2) Nebriinae-type : Nebriinae. The proventriculus is barrel-shaped, with eight clear rows of spines.

3) Elaphrinae-type : Elaphrinae and Broscinae. The mid gut meanders to the right and forms one and half dextral coil, then joins the straight hind gut.

4) Scaritinae-type : Scaritinae. The mid gut meanders to the left and forms one dextral coil. The mid gut meanders conversely in contrast to the other types.

5) Bembidiine-tyte ; Trechinae and Bembidiinae. The hind gut meanders to the right and forms one dextral coil.

6) Pterostichinae-type : Pterostichinae, Zabrinae, Harpalinae, Panagaeinae and Zuphinae. The mid and hind guts meander to the right and forms one dextral coil.

7) Callistinae-type : Callistinae, Patrobinae, Odacanthinae, Lebiinae, and Brachinidae. The mid and hind guts are not coiled.

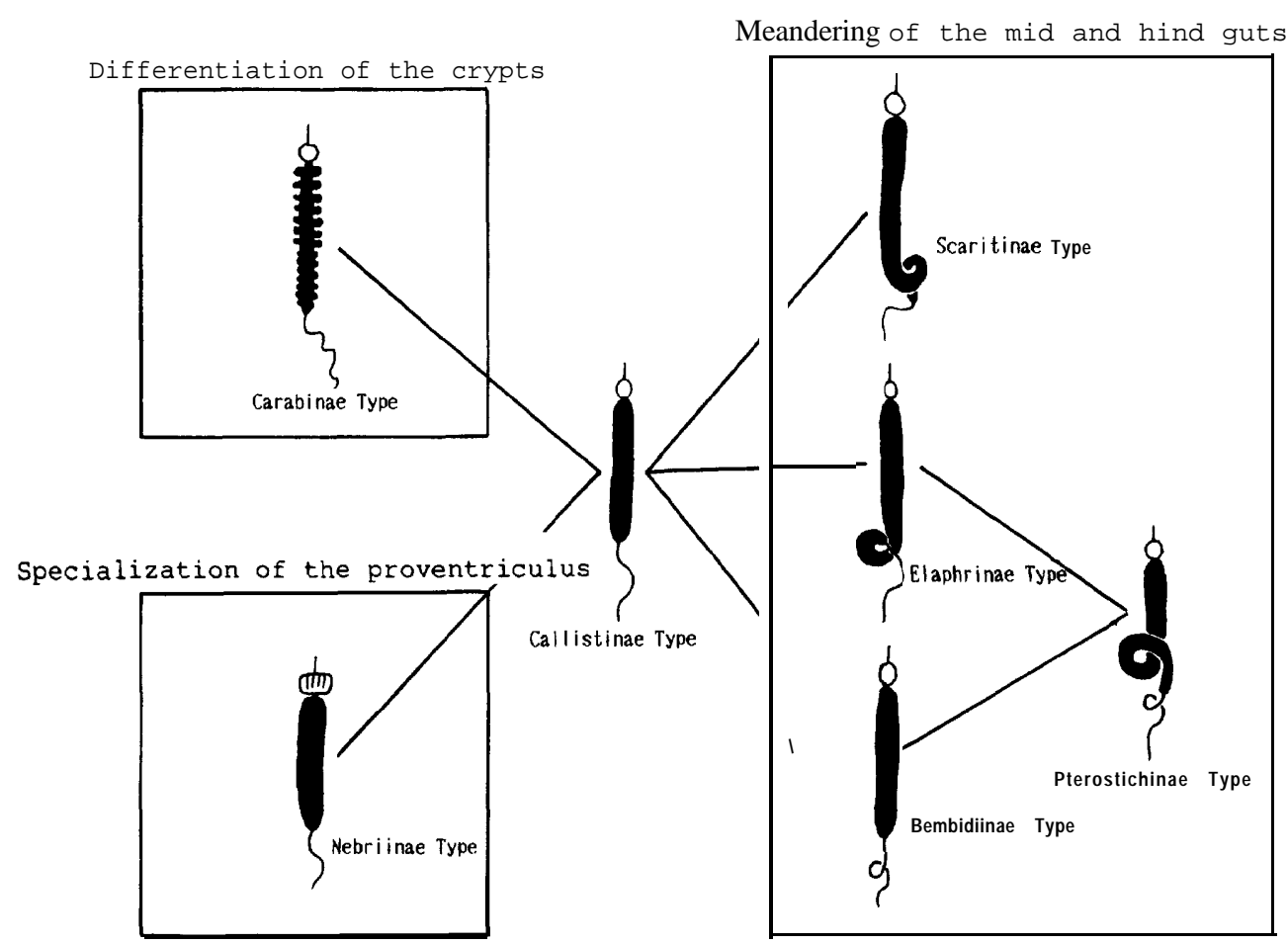

Fig. 33. Schema of the alimentary canal of the ground-beetles. 
The alimentary canal of these 7 types and their relationships are illustrated schematically in Fig. 33. The Callistinae type is the simplest. With this type, the others are connected by lines according to a complication of the characters in question ; namely, specialization of the crypts in the Carabinae-type, development of the spines on the inside of the proventriculus in the Nebriinae-type, and meandering to coiled in the mid and/or hind guts in the others.

The structures of the alimentary canal are, however, strongly affected by foods, and the polarities of the characters examined in this paper are not yet fully analysed at present. The phylogenetic relationships of the higher taxa in the Caraboidea will be inferred in the separate paper from the view points of the histological and functional morphology of the alimentary canal.

\section{Acknowledgements}

I wish to express my cordial thanks to Prof. Emeritus Y. Hirashima and Prof. K. Morimoto (Kyushu Univ.) for their continuous guidance and encouragement. I am also grateful to Dr. S. I. Naomi (Natural History Museum \& Institute, Chiba) for his critical review of the manuscript, to Dr. S. Miyamoto (Chikushi Jogakuen Junior College), Dr. M. Yamamoto, Dr. K. Ogata (Kyushu Univ.) and Assoc. Prof. N. Kôda (Nanzan Univ.) for his kind advice.

I also express my hearty thanks to the following entomologists for their kind help and offering valuable materials, Assoc. Prof. M. T. Chujô (Kyushu Univ.), Dr. S. Miyamoto (Fukuoka), Dr. T. Hirowatari (Osaka Prefectural Univ.), Mr. R. Noda (Fukuoka), Mr. M. Yoshida (National Institute of Agriculutural Science, Ibaraki), Dr. Y. Abe (Natural History Museum \& Institute, Chiba), Dr. 0. Tadauchi, Dr. Y. Sawada, Messers. S. Nomura, M. Abe, T. Yasunaga, Y. Maeda, and Miss Y. Takematsu (Kyushu Univ.).

\section{R eferences}

Ali, H. A., 1967. The higher classification of the Carabidae and the significance of internal characters. Bull. Soc.ent. Egypte, 51: 211-231.

Balfour-Browne, F., 1944. The proventriculus of the Coleoptera (Adephage) and other insects, a study in evolution. J.r.micyosc. Soc., $64: 68-117$.

Ball, G. E., 1979. Conspectus of carabid classification : history, homorphology, and higher taxa. In Erwin et al. Cayabid beetles : their evolution, natural history, and classification: 63-111. Junk.

Bell, R. T. and J. R. Bell, $\quad$ 1962. The taxonomic position of the Rhysodidae. Coleopt. Bull., $16: 99-$ 106.

Bess, M. A., 1935. The alimentary canal of Calosoma sycophanta L. Ohio J. Sci., 35 : 54-64.

Carleton, M., 1936. The anatomy and histology of the alimentary canal of the abult Nebriabrevicollis L. Trans. Soc. By. Ent., 3: 119-127.

Crowson, R. A., 1955. The natural classification of the families of Coleoptera. 187 pp., London.

Davies, M. I., 1953. The contents of the crops of some British carabid beetles. Ent. month. Mag., $89: 18-23$.

Ekis, G. and A. P. Gupta, 1971. Digestive system of Cleridae (Coleoptera). Int.J. Ins. Morph. Embr., 1: $51-86$.

Eliott, P. and P. E. King, 1985. A comparison of rectal pad structure in some terrestrial and intertidal carabid beetles (Insecta). J. nat. Hist., 19(6):1209-1216.

Forsyth, D. J., 1972. The structure of the pygidial glands of Carabidae. Trans. zool.Soc. London, $32: 249-309$. 
Judd, W. W., 1947. The proventriculus of a ground beetle Chlaenius sp. (Col., Carabidae). Canad. Ent., 79 : 58-60.

Kasap, H., 1979. A comparative anatomical study of the alimentary canal of Chrysomeloidea (Coleoptera : Polyphaga). Cummun. Fac. Sci. Univ. Ankara, 22(5) : 53-78.

Kryzhanovsky, 0. L., 1976. An attempt at a revised classification of the family Carabidae. Ent. Oboz., 55: 80-91.

Lindroth, C. H., 1969. The ground-beetles (Carabidae, excl. Cicindelidae) of Canada and Alaska. Opscula Ent. Suppl., Parts 1-6. 1192 pp.

Poll, M., 1932. Contribution à l'étude des tubes de Malpighi des Coléoptères, leur utilité en phylogênèse. Recueil Inst. zool.Torley-Rousseau, 4 : 47-80.

Reichenbach-Klinke, H. H., 1953. Der histologische Aufbau des Proventrikels der Adephaga (Coleoptera) und seine Bedeutung fün Taxonomie und Phylogenie. Mitt.Münch. ent. Ges., 43 : 262-305.

1953. Die Entwicklung des Proventrikels der Coleopteren mit besonderer Berücksichtigung der carnivoren Arten der Unterordnung Polyphaga. Ent. Bl., 49 : 2-17.

Schaefer, P. E., 1931. The alimentary canal of Spaeroderus nitidicollis Chev. var. Schaumi Chd. (Coleoptera). Ohio J. Sci., 41: 181-196.

Shukla, G. S. and V. B. Upadhyay, 1980. A comparative study of morphology of alimentary canal in a saprophagus and camivorus insect. J. anim. Morph. Physiol., 27(1-2): 132-139.

Smrž, J., 1982. Comparative anatomy of proventriculus and intraelytral structure of the suborder Adephaga (Coleoptera). Acta Univ. Carolinae, Biol., 9 : 213-296.

Umeya, K., 1960. A comparative morphology of the alimentary tract in the adults of Lamellicornbeetles (Coleoptera). M em. Fac. Agr. Hokkuido U niv., 3(4) : 60-96.

- 1964. The alimentary canal of Platycerus delicatulus Lewis. Kontyâ, Tokyo, 32(1): 52-54.

Whittington, F. B., 1935. The alimentary canal of Harpalus pennsylvanicus (Col., Carabidae). O hio J. Sci., 35 : 131-135.

Youping, Y., 1987. Comparative anatomy of the alimentary canal of longicorn beetles and their significance in taxonomy (Col., Cerambycidae). Entomotaxonomia, 9:313-320. 